\title{
Matrine and baicalin inhibit apoptosis induced by Panton-Valentine leukocidin of Staphylococcus aureus in bovine mammary epithelial cells
}

\author{
Fang Jia, ${ }^{1,2 *}$ Weiwu Ma, ${ }^{1 *}$ Xiangjun Zhang,,${ }^{1}$ Dong Wang, ${ }^{1}$ and Xuezhang Zhou ${ }^{1} \dagger$ ( \\ ${ }^{1}$ Key Laboratory of the Ministry of Education for the Conservation and Utilization of Special Biological Resources of Western China, \\ Ningxia University, Yinchuan, Ningxia 750021, China \\ ${ }^{2}$ Department of Medicine, Hetao College, BayanNur, Inner Mongolia 015000, China
}

\section{ABSTRACT}

It was previously thought that the Panton-Valentine leukocidin (PVL) toxin of Staphylococcus aureus (S. aureus) was not the main cause of cow mastitis. However, in recent years, detection of the gene encoding PVL has been increasing in dairy cow mastitis, which implies that PVL may be related to bovine mastitis. Therefore, we wanted to search for drugs inhibiting PVL or PVL-induced apoptosis. In this report, we investigated the apoptosis mechanism of PVL in bovine mammary epithelial cells (BMEC) and the inhibition mechanism of matrine and baicalin on PVL-induced apoptosis of BMEC. The results demonstrated that BMEC were damaged and underwent apoptosis by a standard PVLproducing strain of $S$. aureus (ATCC 49775), a PVL knockout mutant $\Delta$ pvl 49775, complemented mutant C- $\Delta$ pvl 49775 , or recombinant (r)PVL in vitro. The rates of apoptosis and necrosis induced by $S$. aureus ATCC 49775 and C- $\Delta$ pvl 49775 were significantly higher than those induced by $\Delta$ pvl 49775 , demonstrating that BMEC apoptosis and necrosis were associated with PVL. In addition, this research found matrine and baicalin could inhibit the apoptosis of BMEC induced by PVL-producing $S$. aureus and by rPVL. Matrine downregulated protein expression levels of endogenous and exogenous cleaved caspase-3, cleaved caspase-8, and cleaved caspase- 9 , and the effect was pronounced at a concentration of $50 \mu \mathrm{g} / \mathrm{mL}$. Baicalin downregulated the expression of cleaved caspase-9. These results suggested that matrine and baicalin may have potential value against cow mastitis caused by the toxin PVL.

Key words: matrine, baicalin, apoptosis, PantonValentine leukocidin

\footnotetext{
Received September 20, 2019.

Accepted November 20, 2019.

*These authors contributed equally to this work.

†Corresponding author: zhouxuezhang@nxu.edu.cn
}

\section{INTRODUCTION}

Staphylococcus aureus is the most common and important pathogen causing bovine mastitis: 10 to $40 \%$ of bovine mastitis cases are caused by $S$. aureus (Kateete et al., 2013; Basanisi et al., 2017; Liu et al., 2017). Various pathogenic factors can adhere to and infect the host, produce inflammatory reactions, and then induce apoptosis of host cells, potentially leading to mammary necrosis during the course of $S$. aureus infection (Zhang et al., 2018). Host cell apoptosis is mainly associated with virulence factors from these pathogenic bacteria, such as $\alpha$-hemolysin, enterotoxin, and Panton-Valentine leukocidin (PVL; Genestier et al., 2005). $\alpha$-Hemolysin induces DNA fragmentation, formation of reactive oxygen species, and alterations in the mitochondrial transmembrane potential in bovine mammary epithelial cells (BMEC; Liu et al., 2014). Recombinant enterotoxin $\mathrm{H}$ directly induces BMEC apoptosis in vitro (Seol et al., 2010). Panton-Valentine leukocidin, one of the main extracellular toxins, is composed of LukS-PV and LukF-PV, 2 proteins secreted by $S$. aureus. First, LukS-PV binds a receptor with high affinity on the host cell membrane, and then LukF-PV binds, forming a dimer that adheres to the cell membrane. These dimers then combine into an octameric ring structure and form pores on the host cell, damaging the cell (Alonzo and Torres, 2014). In recent years, recorded incidence of the PVL gene has been increasing in bovine mastitis and has been as high as $93.8 \%$, as reported in an analysis of the epidemic characteristics of $S$. aureus in fresh cow milk in Beijing in 2018 (Wang et al., 2018). Epidemiological studies have shown that the prevalence of community-acquired methicillin-resistant S. aureus is related to $S$. aureus carriage of the PVL gene (Otter and French, 2010). The PVL gene is also present in a methicillin-sensitive $S$. aureus strain and is related to drug resistance in this strain (Dubos et al., 2014).

Bovine mammary epithelial cells are the first barrier against invading pathogens that have crossed the mechanical barrier at the end of the nipple; BMEC play 
an important role in congenital and specific immune defenses against infection by pathogenic microorganisms (Hu et al., 2014). The major leucocidin secreted by $S$. aureus in bovine mastitis in vivo is LukMF' (Vrieling et al., 2015). However, LukMF' purified in vitro was cytotoxic to bovine neutrophils and macrophages but had no obvious toxic effect on BMEC (Fromageau et al., 2011). No report exists on whether PVL can damage BMEC. In recent years, the detection rate of the PVL gene has increased in bovine mastitis, and PVL is related to the drug resistance of $S$. aureus. Because PVL can kill macrophages and white blood cells, resulting in SCC $<200,000$ cells $/ \mathrm{mL}$ in the milk, about $40 \%$ of PVL-producing S. aureus cases missed detection (Gillet et al., 2002). Considering these factors, it is necessary to study the mechanisms by which PVL damage BMEC, to allow screening of drugs that may repair and decrease this damage.

In recent years, a new strategy of drug targeting has been used to treat bacterial virulence. Several studies have found that matrine can inhibit the secretion of S. aureus $\alpha$-hemolysin (Feng et al., 2018), and baicalin can hinder the cell lysis activity of $\alpha$-hemolysin through a novel mechanism of interrupting the formation of heptamer; this effect has been used successfully in protecting mice from $S$. aureus pneumonia (Qiu et al., 2012). In this study, we used BMEC as an in vitro model to study the molecular mechanism through which PVL-producing $S$. aureus and recombinant PVL (rPVL) damage BMEC. We additionally investigated the protective mechanisms of matrine and baicalin at the cellular and molecular levels in interfering with apoptosis of BMEC induced by PVL-producing $S$. aureus and by rPVL.

\section{MATERIALS AND METHODS}

\section{Cell Culture and Bacteria Growth}

The BMEC cell line (MAC-T) was obtained from Shandong Agricultural University, Tai'an, China, and was cultured in Dulbecco's modified Eagle medium (DMEM)/F-12 (Gibco, Waltham, MA) supplemented with $20 \%$ (vol/vol) fetal bovine serum, $5 \mu \mathrm{g} / \mathrm{mL}$ insulin (Sigma-Aldrich, St. Louis, MO), $1 \mu \mathrm{g} / \mathrm{mL}$ hydrocortisone, $1 \mu \mathrm{g} / \mathrm{mL}$ corporin (Sigma-Aldrich), $5 \mu \mathrm{g} / \mathrm{mL}$ transferrin (Sigma-Aldrich), and antibiotics (100 $\mu \mathrm{g} /$ $\mathrm{mL}$ gentamicin and $100 \mu \mathrm{g} / \mathrm{mL}$ penicillin-streptomycin; Hyclone, Logan, UT) under a $5 \% \mathrm{CO}_{2}$ atmosphere. A standard strain of PVL-producing $S$. aureus (ATCC 49775) was stored in our laboratory, along with rPVL purified by prokaryotic expression. The PVL-knockout mutant strain $\Delta$ pvl 49775 and complemented mutant strain C- $\Delta$ pvl 49775 were obtained from researcher Wanjiang Zhang, of the Harbin Veterinary Research Institute (China). All $S$. aureus strains were grown in tryptic soy broth (TSB; Oxoid Ltd., Basingstoke, UK) at $37^{\circ} \mathrm{C}$, shaken at $120 \mathrm{rpm}$ in a rotary shaker. All plates used to culture cells were from Corning Inc. (Corning, NY).

\section{Drugs and Chemicals}

Matrine (SM8130) and baicalin (SB8020) were purchased from Beijing Solarbio Science and Technology Co. Ltd. (Beijing, China); DMEM/F-12 and fetal bovine serum (FBS) were purchased from Gibco; SYBR Premix Ex Taq II (RR820A) and PrimeScript RT Reagent Kit with gDNA Eraser (RR047A) were purchased from Takara Bio Inc. (Shiga, Japan). The LukS-PV antibody (Cat. No. ab190473), cleaved caspase-3 antibody (ab49822), cleaved caspase-8 antibody (ab25901), $\beta$-actin antibody (ab8227), and goat anti-rabbit IgG (HRP; ab205718) were purchased from Abcam (Cambridge, UK). Cleaved caspase-9 antibody (Cat. No. 10380-1-AP) was purchased from Proteintech (Rosemont, IL). An annexin V-fluorescein isothiocyanate (FITC)/propidium iodide (PI) apoptosis kit (Cat. No. KA3805) was purchased from Abnova (Taipei, Taiwan). The live/dead reagent (Cat. No. KGAF001), whole-cell lysis assay kit (KGP2100), and a bicinchoninic acid (BCA) protein assay kit (KGPBCA) were purchased from Keygen Biotech (Nanjing, China). Hoechst 33342 (Cat. No. C0030) was purchased from Solaibao (Beijing, China).

\section{Cell Viability Assay}

The BMEC were seeded in 96-well plates $\left(1 \times 10^{4}\right.$ per well), allowed to adhere overnight, and the supernatant was discarded. The cells were washed twice in PBS, and $100 \mu \mathrm{L}$ of DMEM/F-12 was added for $12 \mathrm{~h}$ to synchronize the cells. Then the cells were washed twice with PBS, and $100 \mu \mathrm{L}$ of DMEM/F-12 containing matrine at final concentrations of 0 (control), 25, 50, 75, 100, 125 , or $150 \mu \mathrm{g} / \mathrm{mL}$ and baicalin at final concentrations of 0 (control), 2.5, 5, 10, 25, 50, or $100 \mu \mathrm{g} / \mathrm{mL}$ was added and incubated at $37^{\circ} \mathrm{C}$ for $24 \mathrm{~h}$ under $5 \% \mathrm{CO}_{2}$. The cells were then washed twice in PBS, and $110 \mu \mathrm{L}$ of DMEM/F-12 was added to each well, including $10 \mu \mathrm{L}$ of cell counting kit (CCK)-8 reagent (Cat. No. CK04, Dojindo Laboratories, Kumamoto, Japan), and incubated at $37^{\circ} \mathrm{C}$ for $3 \mathrm{~h}$. Finally, the optical density at 450 $\mathrm{nm}$ was measured, and the survival rate was calculated according to kit instructions. A survival rate above $90 \%$ was the goal after drug treatment. 


\section{Cytotoxicity and Cellular Damage}

We seeded BMEC at a concentration of $1.0 \times 10^{5}$ per well in 12-well plates; cells were allowed to adhere for 24 $\mathrm{h}$, then the cells were washed with sterile PBS 3 times. The bacteria (PVL-producing $S$. aureus standard strain ATCC 49775, PVL knockout mutant $\Delta$ pvl 49775, and complemented mutant C- $\Delta$ pvl 49775) were suspended in DMEM/F-12, and $S$. aureus was added; the concentration was adjusted to $1.0 \times 10^{7} \mathrm{cfu} / \mathrm{mL}$ [multiplicity of infection $(\mathrm{MOI})=100]$. The same method was used to add $100 \mathrm{ng} / \mathrm{mL}$ rPVL to BMEC (Supplemental Figure S1, https://doi.org/10.3168/jds.2019-17619). Live/ dead reagent and Hoechst 33342 were added after $3 \mathrm{~h}$ at $37^{\circ} \mathrm{C}$. After incubation at $37^{\circ} \mathrm{C}$ in darkness for 30 min, the staining solution was removed, $100 \mu \mathrm{L}$ of PBS was added, and cells were examined through fluorescence microscopy.

\section{Real-Time $q P C R$}

The influence of matrine and baicalin on the relative expressions of the 2 component proteins of PVL (LukSPV and LukF-PV) and a 2-component RNA III regulatory system from PVL-producing $S$. aureus (standard strain ATCC 49775) were determined via real-time (RT)-qPCR. All primers are shown in Table 1. The concentration of $S$. aureus ATCC 49775 was adjusted

Table 1. The primers for $\mathrm{qPCR}$

\begin{tabular}{|c|c|c|}
\hline $\begin{array}{l}\text { Gene } \\
\text { name }\end{array}$ & Primer sequence $\left(5^{\prime}-3^{\prime}\right)^{1}$ & $\begin{array}{l}\text { Product } \\
\text { length } \\
\text { (bp) }\end{array}$ \\
\hline LukS-PV & $\begin{array}{l}\text { F:GCAATGAGGTGGCCTTTCCA } \\
\text { R:ACCTCCTGTTGATGGACCACT }\end{array}$ & 165 \\
\hline LukF-PV & $\begin{array}{l}\text { F:CGGCTTGTCAGGTGGAGGTA } \\
\text { R:TGCCATATGGTCCCCAACCA }\end{array}$ & 164 \\
\hline RNAIII & $\begin{array}{l}\text { F:TTCACTGTGTCGATAATCCA } \\
\text { R:GGAAGGAGTGATTTCAATGG }\end{array}$ & 158 \\
\hline GyrB & $\begin{array}{l}\text { F:TTATGGTGCTGGGCAAATACA } \\
\text { R:CACCATGTAAACCACCAGATA }\end{array}$ & 188 \\
\hline IL1B & $\begin{array}{l}\text { F:ATGAAGAGCTGCATCCAACACCTG } \\
\text { R:ACCGACACCACCTGCCTGAAG }\end{array}$ & 110 \\
\hline TNFA & $\begin{array}{l}\text { F:CTGGCGGAGGAGGTGCTCTC } \\
\text { R:GGAGGAAGGAGAAGAGGCTGAGG }\end{array}$ & 85 \\
\hline IL6 & $\begin{array}{l}\text { F:CACTGACCTGCTGGAGAAGATGC } \\
\text { R:CCGAATAGCTCTCAGGCTGAACTG }\end{array}$ & 115 \\
\hline $\mathrm{ACTB}$ & $\begin{array}{l}\text { F:CGTCCGTGACATCAAGGAGAAGC } \\
\text { R:GGAACCGCTCATTGCCGATGG }\end{array}$ & 143 \\
\hline CASP3 & $\begin{array}{l}\text { F:GAACCAACGGACCCGTCAAT } \\
\text { R:GCCATGTCATCCTCAGCACC }\end{array}$ & 163 \\
\hline CASP8 & $\begin{array}{l}\text { F:GCTTCATCTGCTGCATCCTCACC } \\
\text { R:AGTCGGTCTCAACGGCTACACC }\end{array}$ & 198 \\
\hline CASP9 & $\begin{array}{l}\text { F:GACGCTGGTTCTGGAGGATTCAC } \\
\text { R:GCGGCAGAAGTTCACGTTGTTG }\end{array}$ & 132 \\
\hline
\end{tabular}

${ }^{1} \mathrm{~F}=$ forward; $\mathrm{R}=$ reverse. to $1.0 \times 10^{7} \mathrm{cfu} / \mathrm{mL}$, and fresh medium was added at 1:100 with matrine and baicalin, for final concentrations of matrine at 0 (control), 25, 50, or $100 \mu \mathrm{g} / \mathrm{mL}$ and baicalin at 0 (control), 2.5, 5, or $10 \mu \mathrm{g} / \mathrm{mL}$. The solution was then incubated in a rotary shaker at $37^{\circ} \mathrm{C}$, at $120 \mathrm{rpm}$, for $24 \mathrm{~h}$. Total RNA of the bacterial fluid (S. aureus ATCC 49775) was extracted according to the manufacturer's instructions (http://www.tiangen .com/asset/imsupload/up0531252001567739982.pdf).

The relative expression of the proinflammatory factors IL-1 $\beta$, TNF- $\alpha$, and IL-6, and the apoptotic factors caspase 3,8 , and 9 from BMEC induced by recombinant rPVL was determined by RT-qPCR. The numbers and methods of BMEC culture were as in the section Cytotoxicity and Cellular Damage. Total RNA of cells was extracted and immediately reverse-transcribed into cDNA. The reaction system contained $25 \mu \mathrm{L}$, comprising $12.5 \mu \mathrm{L}$ of $2 \times$ SYBR Premix Ex Taq II, $1 \mu \mathrm{L}$ each of upstream and downstream primers $(10 \mu M), 2 \mu \mathrm{L}$ of cDNA, and $8.5 \mu \mathrm{L}$ of double-distilled water. Three replicates were analyzed per sample. The PCR was performed at $95^{\circ} \mathrm{C}$ for $3 \mathrm{~min}, 95^{\circ} \mathrm{C}$ for $5 \mathrm{~s}$, and $60^{\circ} \mathrm{C}$ for 30 $\mathrm{s}$ for 40 cycles. The RT-qPCR data were analyzed using the $2^{-\Delta \Delta \mathrm{Ct}}$ method.

\section{ELISA Assay}

The concentrations of rPVL-induced proinflammatory factors IL-1 $\beta$, TNF- $\alpha$, and IL-6 were measured using the ELISA assay. The numbers and method of BMEC calculation are the same as those described in the section Cytotoxicity and Cellular Damage. The supernatants of all the treatment groups were collected after centrifugation at $1,000 \times g$ for $10 \mathrm{~min}$. Each group of 3 replicates was measured using the ELISA kit in accordance with the operating instructions (www.elisakit .cc). A standard curve was drawn and used to calculate the concentration of rPVL for each treatment group in the sample.

\section{Western Blot Analysis}

The concentrations and incubation methods for $S$. aureus ATCC 49775 and its mutants were as described in the Real-Time qPCR section. The supernatant was collected after centrifugation at $8,000 \times g$ at $4^{\circ} \mathrm{C}$ for 10 min. Then the supernatant was transferred to a new tube, and protein content was detected via the BCA method. The amount of each protein loaded was adjusted to $20 \mu \mathrm{g} /$ well with deionized water for SDS-PAGE. The BMEC were inoculated at $5.0 \times 10^{5}$ per well in 6 -well plates, and the other steps were as described in the Cytotoxicity and Cellular Damage section. Total 
BMEC protein was extracted with a whole-cell lysis assay kit, and protein content was detected using the BCA method, with protein loaded at $20 \mu \mathrm{g}$ in each well for SDS-PAGE. The SDS-PAGE was performed with a $12.5 \%$ gel. Anti-LukS-PV rabbit polyclonal antibody was diluted 1:3,000, anti-cleaved caspase-3 was diluted 1:500, cleaved caspase- 8 was diluted 1:1,000, cleaved caspase-9 was diluted 1:300, and $\beta$-actin was diluted 1:1,000. The HRP goat anti-rabbit IgG antibody was diluted 1:24,000. One Tris-buffered saline Tween 20 (TBST) eluent was used to wash the membrane 3 times, and this was followed by enhanced chemiluminescence (ECL) detection.

\section{Flow Cytometry}

In 6-well plates, BMEC were inoculated at $5.0 \times$ $10^{5}$ cells per well. The drug treatment concentrations and methods were as described in the Cytotoxicity and Cellular Damage and Real-Time qPCR sections. Cells were suspended in $500 \mu \mathrm{L}$ of binding buffer, and $5 \mu \mathrm{L}$ of annexin V-FITC and $5 \mu \mathrm{L}$ of PI were added and incubated at $37^{\circ} \mathrm{C}$ in the dark for $15 \mathrm{~min}$. Apoptosis was observed using flow cytometry.

\section{Statistical Analysis}

All data are presented as mean \pm standard deviation (SD), and experiments were repeated at least 3 times. Statistical testing was carried out with $t$-tests for 2 samples or ANOVA for multiple samples, and multiple samples were compared in pairs using the Dunnett $t$ test.

\section{RESULTS}

\section{S. aureus Strains Producing PVL and rPVL Induced Morphological Damage and Apoptosis of BMEC}

Staphylococcus aureus PVL and rPVL inhibited the proliferation of BMEC and caused morphological damage, as measured by live/dead cell fluorescence staining. Live cells appeared green, whereas dead cells appeared red under an inverted fluorescence microscope. Damage to BMEC was caused within $3 \mathrm{~h}$ by $S$. aureus ATCC 49775, $\Delta$ pvl 49775, and C- $\Delta$ pvl 49775 (Figure $1 \mathrm{~A})$. The rPVL also damaged BMEC in $3 \mathrm{~h}$ and showed increasing toxicity to cells over time. The nuclei of affected BMEC showed chromatin condensation, vacuolated DNA fragmentation, and apoptosis (Figure 1B). Hoechst 33342 nuclear staining was used to observe the damage to BMEC caused by rPVL (Figure 1C).

Staphylococcus aureus PVL induced apoptosis in BMEC, as shown by annexin V/PI staining. Apoptosis and necrosis among BMEC were significantly induced by $S$. aureus ATCC $49775, \Delta$ pvl 49775 and C- $\Delta$ pvl 49775 to different degrees after $6 \mathrm{~h}$, compared with the control group (Figure 2A). The rates of apoptosis and necrosis induced by $S$. aureus ATCC 49775 and C- $\Delta$ pvl 49775 were significantly higher than those induced by $\Delta$ pvl $49775(P<0.05$; Figure $2 \mathrm{~A})$, indicating that PVL secretion enhances the virulence of $S$. aureus. Levels of apoptosis in BMEC induced by rPVL were significantly different from those in the control group $(P<0.01)$. Apoptosis was induced in BMEC by rPVL after $30 \mathrm{~min}$, and the apoptosis rate increased over time (Figure 2B).

\section{rPVL Induced Expression of Apoptosis-Related Factor Caspase-3, -8, and -9 in BMEC}

Our experiment proved that rPVL can induce apoptosis of BMEC, and we further explored the possible mechanism through which this occurs. In BMEC, the relative expression of the apoptosis-related factors caspase-3, 8, and 9 was detected using RT-qPCR and Western blotting. The RT-qPCR results indicated that the mRNA expression of caspase-3, 8, and 9 induced in BMEC by rPVL was significantly higher than that of the control group after $30 \mathrm{~min}(P<0.01$; Supplemental Figure S2, https://doi.org/10.3168/jds.2019-17619). This was consistent with Western blot results, in which BMEC expressed extremely low levels of caspase- 3,8 , and 9 proteins in the control group, whereas pretreatment with $100 \mathrm{ng} / \mathrm{mL}$ rPVL significantly activated caspase-3, 8, and 9 (Figure 2C). The results showed that rPVL induced apoptosis of BMEC through the caspase-dependent pathway.

\section{$r P V L$ Induced Expression of Inflammatory Factors in BMEC}

Expression of the cytokines IL-1 $\beta$, IL-6, and TNF- $\alpha$ in BMEC, as induced by rPVL, was detected via ELISA and RT-qPCR. The ELISA results showed that expression of IL-1 $\beta$ significantly increased at $30 \mathrm{~min}(P<$ 0.01 ; Figure 3 ), but expression of IL- 6 and TNF- $\alpha$ were significantly changed after $1 \mathrm{~h}$. The RT-qPCR results for the relative expression of IL-1 $\beta$ were consistent with the ELISA results at $30 \mathrm{~min}$ (Supplemental Figure S3, https://doi.org/10.3168/jds.2019-17619). Expression of IL-6 and TNF- $\alpha$ in BMEC showed the greatest increases at $1 \mathrm{~h}$ and $6 \mathrm{~h}$ (Supplemental Figure S3).

\section{Safe Concentrations of Matrine and Baicalin}

The potential cytotoxicity of different concentrations of matrine and baicalin were evaluated using a cell 

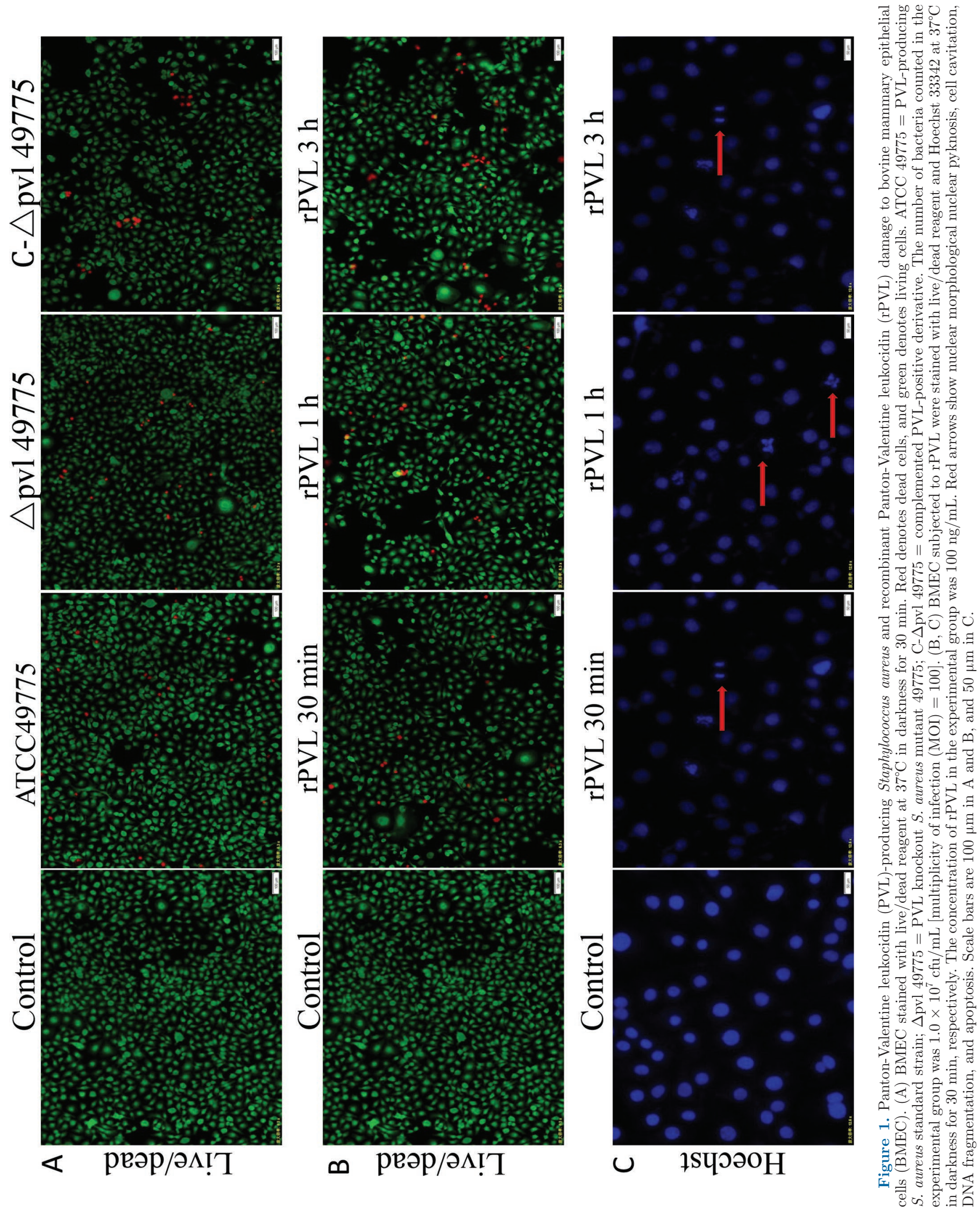


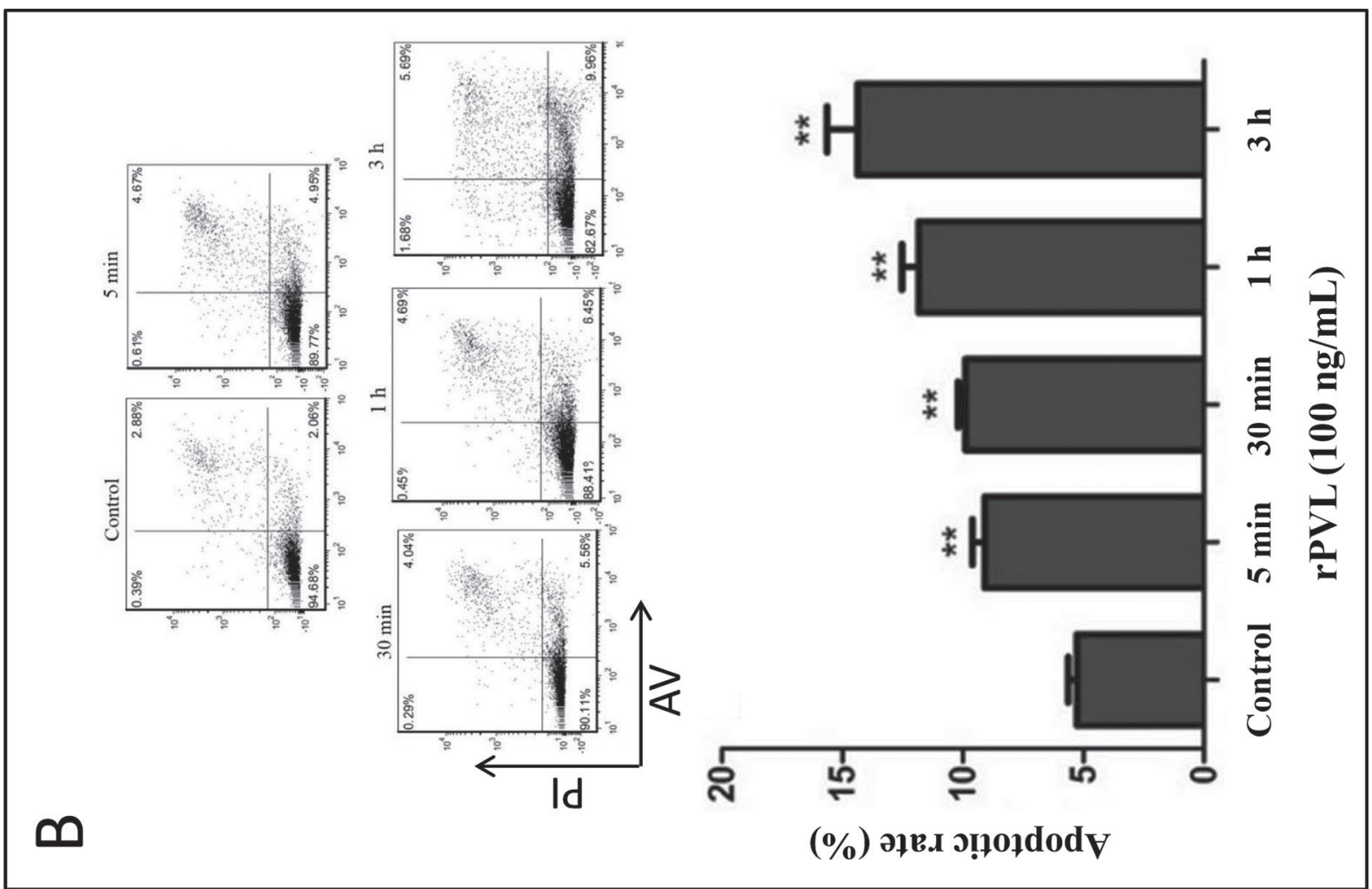

这全光
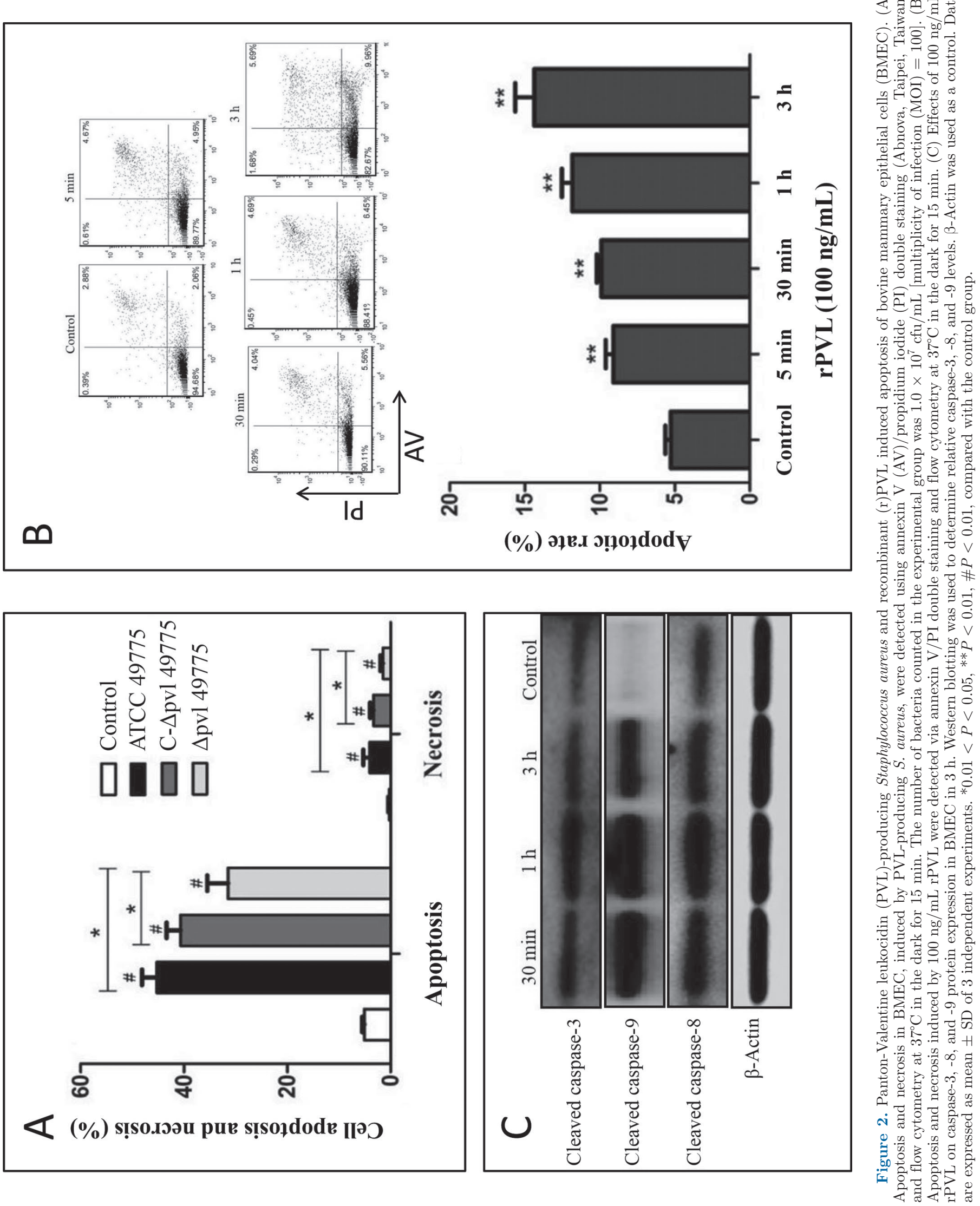


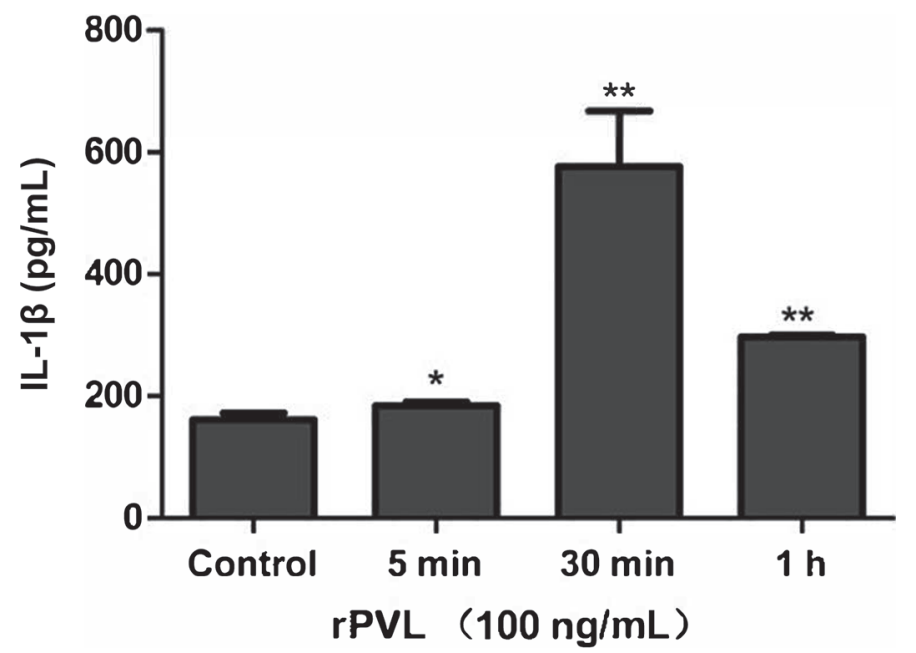

Figure 3. Recombinant Panton-Valentine leukocidin (rPVL) induced expression of the inflammatory factor IL-1 $\beta$ in bovine mammary epithelial cells (BMEC). BMEC were treated with $100 \mathrm{ng} / \mathrm{mL} \mathrm{rPVL}$ and cultured at $37^{\circ} \mathrm{C}$ for $3 \mathrm{~h}$. The level of IL- $1 \beta$ in cell supernatants was determined using ELISA. Data are expressed as mean \pm SD of 3 independent experiments. ${ }^{*} 0.01<P<0.05,{ }^{*} P<0.01$.

counting kit (CCK-8) assay after incubation of BMEC for $24 \mathrm{~h}$. The 2 drugs have different effects on the proliferation of BMEC. Matrine promoted proliferation of BMEC at 25, 50, 75, and $100 \mu \mathrm{g} / \mathrm{mL}$, whereas baicalin did not inhibit proliferation of BMEC under $10 \mu \mathrm{g} / \mathrm{mL}$ after $24 \mathrm{~h}$ (Figure 4). The latter result indicates that cytotoxicity was not observed in BMEC at baicalin concentrations of 2.5 to $10 \mu \mathrm{g} / \mathrm{mL}$, but BMEC did not proliferate. Matrine and baicalin showed clear cytotoxicity to BMEC at concentrations of 125 to $150 \mu \mathrm{g} / \mathrm{mL}$ and 25 to $100 \mu \mathrm{g} / \mathrm{mL}$, respectively. Safe concentrations of matrine and baicalin were found to be 25 to $100 \mu \mathrm{g} /$ $\mathrm{mL}$ and 2.5 to $10 \mu \mathrm{g} / \mathrm{mL}$, respectively.

\section{Matrine and Baicalin Can Inhibit Apoptosis of BMEC Induced by S. aureus-Produced PVL and rPVL}

Both matrine and baicalin significantly decreased BMEC apoptosis induced by PVL-producing $S$. aureus ATCC 49775, compared with the $S$. aureus group alone (ATCC 49775). This effect was observed at matrine concentrations of 25 and $50 \mu \mathrm{g} / \mathrm{mL}(P<0.01)$. However, the effect was not concentration-dependent, and the best protection effect was observed at $50 \mu \mathrm{g} / \mathrm{mL}$, as indicated by annexin V/PI double staining and flow cytometry. The protective effect in apoptotic cells was significant with concentrations of 2.5 to $10 \mu \mathrm{g} / \mathrm{mL}$ of baicalin, compared with the $S$. aureus group alone (ATCC 49775; $P<0.01$; Figure 5B), and this result was concentration-dependent.

These results showed that matrine and baicalin inhibit apoptosis of BMEC induced by PVL-producing $S$. aureus. Thus, we sought to verify that matrine and baicalin had the same inhibiting effects on apoptosis induced by rPVL. Both matrine and baicalin reduced the rate of BMEC apoptosis induced by $\mathrm{PPVL}$, on the basis of annexin V/PI staining and flow cytometry. We found a significant difference in cells treated with matrine at 50 and $100 \mu \mathrm{g} / \mathrm{mL}$ (Figure 5C) and baicalin at $10 \mu \mathrm{g} / \mathrm{mL}$ (Figure 5D), compared with the control group (rPVL alone; $P<0.01$ ). These results suggested that matrine and baicalin have protective effects in BMEC exposed to rPVL.
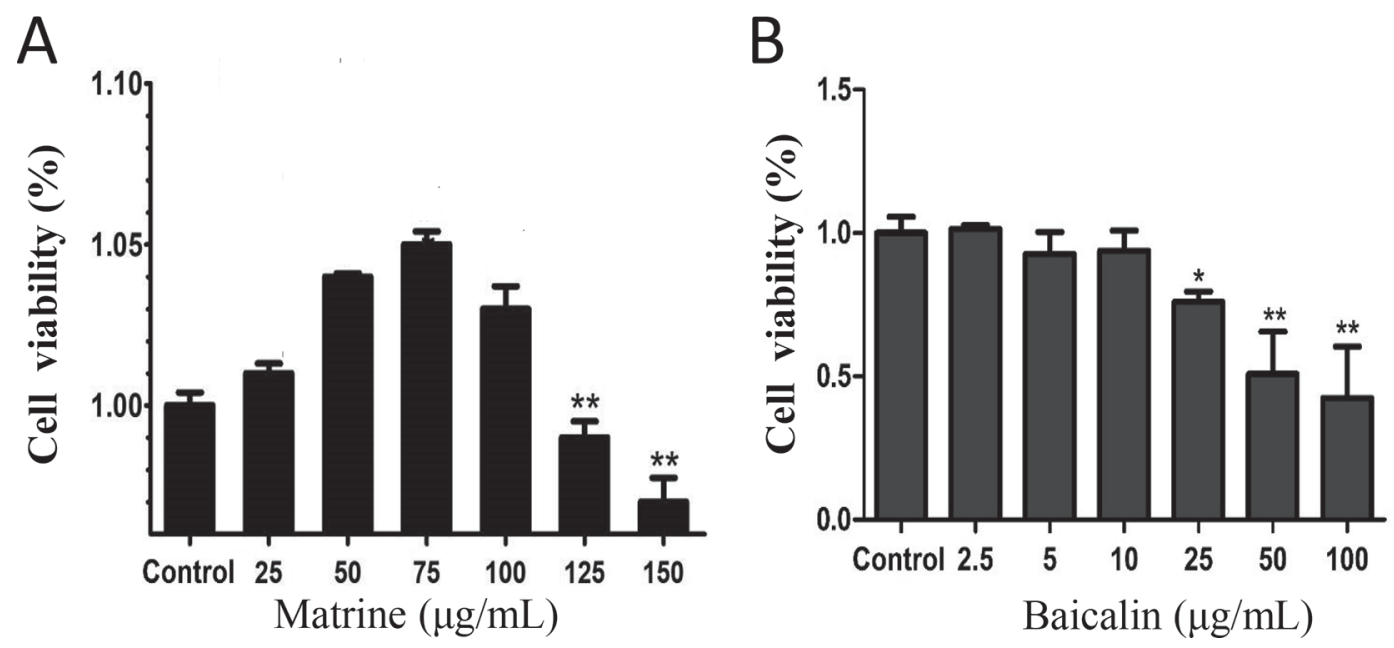

Figure 4. Matrine and baicalin affected the viability of bovine mammary epithelial cells (BMEC). The viability of BMEC treated for $24 \mathrm{~h}$ with the indicated concentrations of matrine and baicalin was measured using a CCK-8 cell counting assay (Dojindo Laboratories, Kumamoto, Japan) after $3 \mathrm{~h}$. Data are expressed as mean $\pm \mathrm{SD}$ of 3 independent experiments. ${ }^{*} 0.01<P<0.05,{ }^{* *} P<0.01$. 
Matrine and Baicalin Inhibited Expression in BMEC of the rPVL-Induced Apoptosis-Related Factors Caspase-3, -8, and -9

We next sought to confirm the mechanism through which matrine and baicalin inhibit apoptosis of BMEC induced by rPVL. We detected expression of the apoptosis-related factors caspase-3, 8, and 9 in BMEC via Western blotting. Matrine downregulated the protein expression of endogenous and exogenous cleaved caspase- 3 , cleaved caspase- 8 , and cleaved caspase- 9 in BMEC, with effects apparent at a concentration of 50
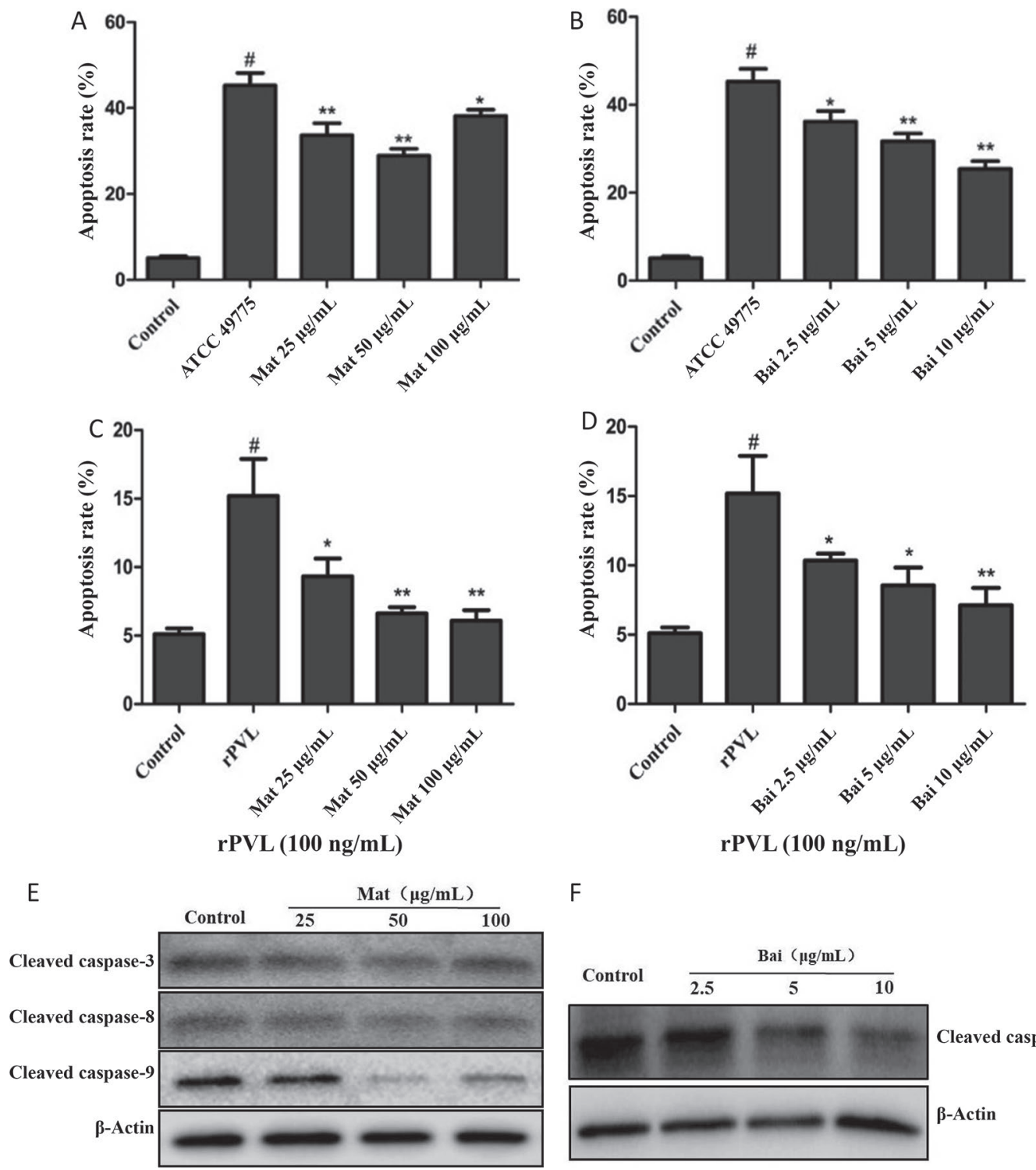

F

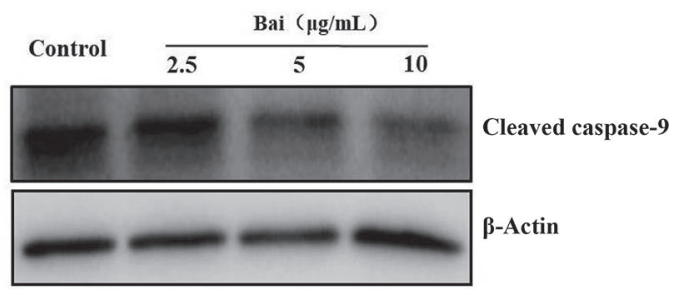

Figure 5. Matrine and baicalin inhibit apoptosis of bovine mammary epithelial cells (BMEC) induced by Panton-Valentine leukocidin (PVL)-producing Staphylococcus aureus and recombinant (r)PVL. (A, B) BMEC were pretreated with matrine and baicalin at $37^{\circ} \mathrm{C}, 5 \% \mathrm{CO}_{2}$, for $3 \mathrm{~h}$ in the absence or presence of PVL-producing S. aureus ATCC 49775. (C, D) BMEC were pretreated with matrine and baicalin at $37^{\circ} \mathrm{C}, 5 \%$ $\mathrm{CO}_{2}$, for $3 \mathrm{~h}$ in the absence or presence of rPVL. Apoptotic cells were determined using annexin V/propidium iodide double staining (Abnova, Taipei, Taiwan) and flow cytometry. Data are expressed as mean \pm SD of 3 independent experiments. \#P<0.01 compared with control group; ${ }^{*} P<0.05,{ }^{* *} P<0.01$ compared with $S$. aureus group alone. (E, F) Inhibition of matrine and baicalin apoptosis factors caspase-3, -8 , and -9 protein expression levels in BMEC exposed to rPVL. Cell processing is as described for panels C and D. $\beta$-Actin was used as a control. Western blotting was used to determine relative protein expression levels. Mat = matrine; bai = baicalin. 
$\mu \mathrm{g} / \mathrm{mL}$ (Figure $5 \mathrm{E}$ ). In addition, baicalin downregulated the expression of cleaved caspase-9, which is involved in the endogenous pathway of apoptosis (Figure 5F).

\section{Baicalin Decreased Expression of S. aureus RNA III}

Two proteins compose PVL: LukS-PV and LukFPV. Endogenous RNA III regulates the expression of virulence factors belonging to a 2-component regulatory system in $S$. aureus. The relative expressions of LukS-PV, LukF-PV, and RNA III in S. aureus were analyzed using RT-qPCR (Figure 6A). Matrine did not affect the expression of LukS-PV, LukF-PV, or RNA III in S. aureus. Notably, baicalin did not affect the expression of LukS-PV or LukF-PV, but it decreased the expression of RNA III in S. aureus.

\section{Matrine and Baicalin Reduced Secretion of LukS-PV from S. aureus}

The RT-qPCR results showed that matrine and baicalin did not inhibit expression of LukS-PV or LukF$\mathrm{PV}$ in $S$. aureus. We further used Western blotting to examine whether matrine and baicalin might affect the protein expression level of LukS-PV in S. aureus. In line with our expectation, matrine and baicalin can reduce the protein expression level of LukS-PV in $S$. aureus. Unexpectedly, the results showed that matrine
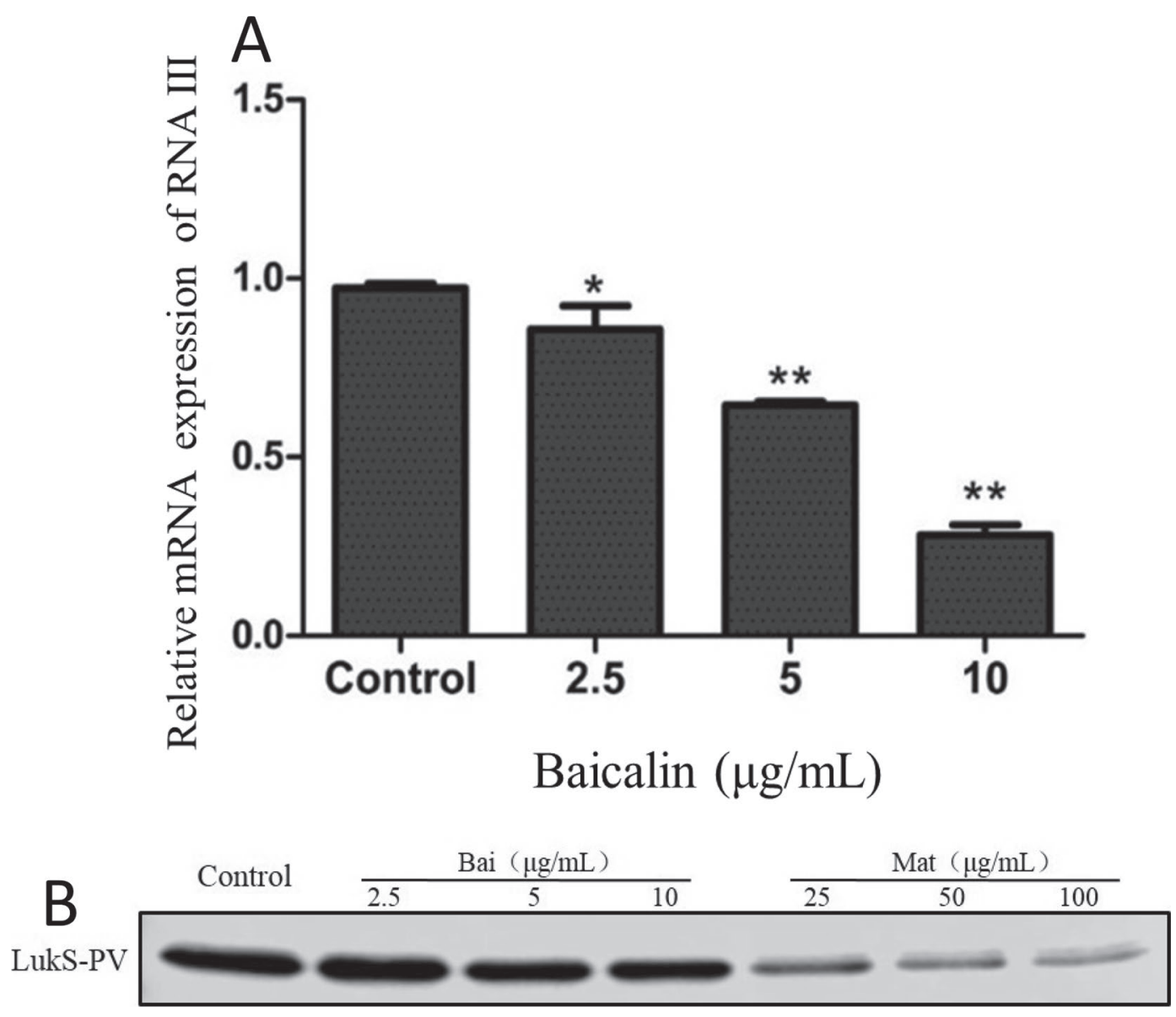

Figure 6. Matrine and baicalin affected expression of RNA III and the protein LukS-PV by Staphylococcus aureus. (A) Baicalin affected mRNA expression of RNA III in S. aureus. Staphylococcus aureus ATCC $49775\left(1.0 \times 10^{7} \mathrm{cfu} / \mathrm{mL}\right)$ was treated with matrine $(0,25,50$, or 100 $\mathrm{mg} / \mathrm{mL})$ and baicalin $(0,2.5,5$, or $10 \mu \mathrm{g} / \mathrm{mL})$ for $24 \mathrm{~h}$. Relative expression of RNA III was determined via real-time quantitative PCR. Data are expressed as mean \pm SD of 3 independent experiments. ${ }^{*} 0.01<P<0.05,{ }^{*} P<0.01$. (B) Matrine and baicalin inhibited secretion of LukS-PV by $S$. aureus. Staphylococcus aureus ATCC $49775\left(1.0 \times 10^{7} \mathrm{cfu} / \mathrm{mL}\right)$ was treated with matrine $(0,25,50$, or $100 \mathrm{mg} / \mathrm{mL})$ and baicalin $(0,2.5$, 5 , or $10 \mu \mathrm{g} / \mathrm{mL}$ ) for $24 \mathrm{~h}$. The supernatant of the bacterial suspension was used to determine LukS-PV expression levels via Western blotting. Mat $=$ matrine; bai $=$ baicalin. 
inhibited the expression of LukS-PV to a greater extent than baicalin $(P<0.01$; Figure $6 \mathrm{~B})$.

\section{DISCUSSION}

This study demonstrated that matrine and baicalin inhibit BMEC apoptosis induced by PVL-producing $S$. aureus and by rPVL, by downregulating the protein expression of endogenous and exogenous cleaved caspase-3, cleaved caspase-8, and cleaved caspase-9. Staphylococcus aureus first adheres to infected sites and proliferates, producing a variety of toxins and invasive enzymes that induce host cell inflammation and apoptosis. Endogenous PVL is a 2-component porotoxin comprising LukS-PV and LukF-PV, which form dimers that are secreted by $S$. aureus and that subsequently damage cells. In our study, we observed that BMEC exposed for $3 \mathrm{~h}$ to PVL from S. aureus ATCC 49775, $\Delta$ pvl 49775, and C-pvl 49775 showed characteristics of chromatin condensation, DNA fragmentation, and appearance of apoptosis. Apoptosis and necrosis of mammary epithelial cells occurred after treatment. The apoptosis and necrosis rates induced in BMEC by S. aureus ATCC 49775 and C-pvl 49775 were significantly higher than those induced by $\Delta$ pvl $49775(P<$ 0.05 ), suggesting that production of PVL enhanced the virulence of $S$. aureus. Preliminary results showed that production of PVL did not affect the ability of $S$. aureus to adhere to and invade cells (Supplemental Figure S4, https://doi.org/10.3168/jds.2019-17619). As shown in studies of human cutin cells, PVL does not influence the level of infection, but PVL-producing strains can escape the body's defense mechanisms, increasing $S$. aureus proliferation in the cytoplasm and inducing apoptosis through caspase-dependent mechanisms (Chi et al., 2014). Treatment with $5 \mathrm{n} M$ rPVL resulted in typical characteristics of neutrophilic granulocyte apoptosis after $6 \mathrm{~h}$. Cell necrosis was induced by treating cells with $200 \mathrm{n} M \mathrm{rPVL}$ for $1 \mathrm{~h}$, indicating that the main pathway through which PVL induces neutrophil apoptosis is the mitochondrial pathway (Genestier et al., 2005; Saïd-Salim et al., 2005). Recombinant PVL produced clear cytotoxic changes in BMEC after $3 \mathrm{~h}$ in vitro at 40 to $100 \mathrm{ng} / \mathrm{mL}(P<0.01)$. However, questions remain regarding the target cell and species specificity of PVL. Studies have shown that PVL has strong and rapid cytotoxicity toward neutrophils in humans and rabbits but no effect on immune cells in mice and monkeys (Löffler et al., 2010).

At present, we know of 3 main apoptosis pathways: death receptor, mitochondrial, and endoplasmic reticulum pathways. The death receptor pathway uses the death receptors on the cell membrane to activate caspase- 8 and further activate downstream caspase proteins to induce apoptosis. The mitochondrial pathway releases apoptotic factors, such as cytochrome C (Cytc), through mitochondria in the cytoplasm. Cytochrome $\mathrm{C}$ forms a complex with apoptotic protease activation factors and recruits the precursor of caspase-9. After caspase-9 self-activation, downstream caspase-3 is activated, and apoptosis is induced. The endoplasmic reticulum pathway is activated after the endoplasmic reticulum calcium balance is destroyed. Subsequently, caspase-12 expression is upregulated, and caspase-7 is transferred to the endoplasmic reticulum surface, where it activates caspase-12, resulting in activation of a caspase-12 cascade, which further alters caspase-3 and induces apoptosis (Julien and Wells, 2017). In our study, rPVL induced apoptosis of BMEC after 30 min, and the apoptosis rate increased with increasing treatment time $(P<0.01)$. The expression of the apoptosis-related factors caspase-3, 8 , and 9 detected by RT-qPCR and Western blotting showed that rPVL significantly upregulated the expression of caspase-3, 8 , and 9 in BMEC after 30 min $(P<0.01)$. This study revealed that both the death receptor pathway and the mitochondrial pathway are involved in rPVL induction of BMEC apoptosis. Moreover, this study found that inflammatory factor IL-1 $\beta$ is first secreted by BMEC exposed to PVL. Relatively speaking, the expression levels of IL- 6 and TNF- $\alpha$ were delayed for $1 \mathrm{~h}$ and 6 $\mathrm{h}$, respectively, in BMEC exposed to rPVL. Previous studies have found that the inflammasome NLRP3 regulates caspase-1 activation, leading to release of IL-1 $\beta$, and IL-18 and caspase-1 cleave gasdermin-D, inducing pyroptosis; thus, PVL appears to lead to pyroptosis of BMEC (Shi et al., 2015; Liu et al., 2016).

Matrine and baicalin have been used clinically because of their anti-inflammatory, bacteriostatic, allergenic, and immune-enhancing pharmacological effects. Matrine can effectively alleviate LPS-induced lung injury by reducing reactive oxygen species, TNF- $\alpha$, IL-6, and other inflammatory factors (Zhang et al., 2011). Baicalin decreases LPS-induced inflammation and apoptosis in mammary epithelial cells by regulating NF- $\kappa \beta$ and HSP72 (Yang et al., 2016). In this study, both matrine and baicalin restrained PVL-induced apoptosis in BMEC $(P<0.01)$. In brief, matrine and baicalin also had a protective effect in BMEC. The optimal concentration of baicalin was 2.5 to $10 \mu \mathrm{g} / \mathrm{mL}$, and matrine had the best protective effect at $50 \mu \mathrm{g} /$ $\mathrm{mL}$. At the same time, we also explored the molecular mechanisms by which matrine and baicalin inhibited PVL-induced apoptosis of BMEC. Western blotting results showed that baicalin downregulated the expression of cleaved caspase-9 in the mitochondrial pathway $(P<0.01)$, and matrine downregulated the expression of the apoptosis factors cleaved caspase- 8 , cleaved cas- 
pase-3, and cleaved caspase-9 in BMEC through the mitochondrial pathway $(P<0.01)$.

We also investigated the effects of matrine and baicalin on the mRNA and protein expression levels of LukS-PV in PVL-producing S. aureus ATCC 49775. The binary regulation system of $S$. aureus, to which RNA III belongs, can regulate the expression and regulation of $S$. aureus virulence factors. Boisset et al. (2007) found that $S$. aureus RNA III coordinately represses the synthesis of virulence factors and the transcription regulator Rot by an antisense mechanism, whereas the total PVL transcript level of $S$. aureus is decreased when the agr gene is absent (Koenig et al., 2004). Baicalin downregulated the expression of RNA III in the dual regulatory system of $S$. aureus at transcription levels, suggesting that baicalin may inhibit $S$. aureus expression of PVL through RNA III regulation. Matrine inhibited the expression of LukS-PV more effectively than did baicalin at protein expression levels $(P<0.01)$. Matrine cannot effectively inhibit the activity of $S$. aureus, but it can repress the expression of $\alpha$-hemolysin and the toxin secretion of $S$. aureus (Feng et al., 2018). Therefore, matrine and baicalin can be considered potential drugs to inhibit infection caused by PVL from $S$. aureus.

\section{CONCLUSIONS}

The PVL activity of $S$. aureus is correlated with BMEC apoptosis. Matrine inhibited BMEC apoptosis partly through a mechanism of downregulating protein expression of cleaved caspase-3, cleaved caspase-8, and cleaved caspase- 9 , and the effect was marked at a $50 \mu \mathrm{g} / \mathrm{mL}$ concentration. However, baicalin inhibited BMEC apoptosis partly through downregulation of cleaved caspase-9 expression.

\section{ACKNOWLEDGMENTS}

The authors thank Shandong Agricultural University (China) for providing the MAC-T cell line and thank researcher Wanjiang Zhang at the Harbin Veterinary Research Institute (China) for providing the PVLknockout mutant strain $\Delta$ pvl 49775 and the complemented mutant strain C- $\Delta$ pvl 49775. X. Z. conceived of and designed the protocols for experiments; F. J., W. M., X. Z., and J. F. performed the experiments and analyzed the data. F. J. organized and drafted the manuscript; all authors read and approved the final version of the manuscript. This study was supported by grants from the National Natural Science Foundation of China (No. 31660728; Beijing) and the Major Innovation Projects for Building First-class Universities in China's Western Region (ZKZD2017001; Yinchuan,
China). These funders had no role in study design, data collection and analysis, decision to publish, or preparation of the manuscript. The authors declare that they have no conflicts of interest.

\section{REFERENCES}

Alonzo, F. 3rd, and V. J. Torres. 2014. The bicomponent pore-forming leucocidins of Staphylococcus aureus. Microbiol. Mol. Biol. Rev. 78:199-230. https://doi.org/10.1128/MMBR.00055-13.

Basanisi, M. G., G. La Bella, G. Nobili, I. Franconieri, and G. La Salandra. 2017. Genotyping of methicillin-resistant Staphylococcus aureus (MRSA) isolated from milk and dairy products in South Italy. Food Microbiol. 62:141-146. https://doi.org/10.1016/j.fm .2016.10.020.

Boisset, S., T. Geissmann, E. Huntzinger, P. Fechter, N. Bendridi, M. Possedko, C. Chevalier, A. C. Helfer, Y. Benito, A. Jacquier, C. Gaspin, F. Vandenesch, and P. Romby. 2007. Staphylococcus aureus RNAIII coordinately represses the synthesis of virulence factors and the transcription regulator Rot by an antisense mechanism. Genes Dev. 21:1353-1366. https://doi.org/10.1101/gad.423507.

Chi, C. Y., C. C. Lin, I. C. Liao, Y. C. Yao, F. C. Shen, C. C. Liu, and C. F. Lin. 2014. Panton-Valentine leukocidin facilitates the escape of Staphylococcus aureus from human keratinocyte endosomes and induces apoptosis. J. Infect. Dis. 209:224-235. https://doi.org/10 $.1093 /$ infdis/jit445.

Dubos, M., O. Barraud, A. L. Fedou, F. Fredon, F. Laurent, Y. Brakbi, A. Cypierre, and B. Francois. 2014. Prostatic abscesses and severe sepsis due to methicillin-susceptible Staphylococcus aureus producing Panton-Valentine leukocidin. BMC Infect. Dis. 14:466. https://doi.org/10.1186/1471-2334-14-466.

Feng, F., M. M. Wa, H. X. Luo, C. P. Guan, and X. Z. Zhou. 2018. Effect of matrine on reducing damage to bovine mammary epithelial cells induced by Staphylococcus aureus alpha-hemolysin. Pol. J. Vet. Sci. 21:409-413. https://doi.org/10.24425/122610.

Fromageau, A., P. Cunha, F. B. Gilbert, and P. Rainard. 2011. Purified Staphylococcus aureus leukotoxin LukM/F' does not trigger inflammation in the bovine mammary gland. Microb. Pathog. 51:396-401. https://doi.org/10.1016/j.micpath.2011.09.005.

Genestier, A. L., M. C. Michallet, G. Prévost, G. Bellot, L. Chalabreysse, S. Peyrol, F. Thivolet, J. Etienne, G. Lina, F. M. Vallette, F. Vandenesch, and L. Genestier. 2005. Staphylococcus aureus Panton-Valentine leukocidin directly targets mitochondria and induces Bax-independent apoptosis of human neutrophils. J. Clin. Invest. 115:3117-3127. https://doi.org/10.1172/JCI22684.

Gillet, Y., B. Issartel, P. Vanhems, J.-C. Fournet, G. Lina, M. Bes, F. Vandenesch, Y. Piémont, N. Brousse, D. Floret, and J. Etienne. 2002. Association between Staphylococcus aureus strains carrying gene for Panton-Valentine leukocidin and highly lethal necrotising pneumonia in young immunocompetent patients. Lancet 359:753759. https://doi.org/10.1016/S0140-6736(02)07877-7.

Hu, Q., X. Cui, L. Tao, L. Xiu, T. Wang, and X. Wang. 2014. Staphylococcus aureus induces apoptosis in primary bovine mammary epithelial cells through Fas-FADD death receptor-linked caspase-8 signaling. DNA Cell Biol. 33:388-397. https://doi.org/10.1089/ dna.2013.2195.

Julien, O., and J. A. Wells. 2017. Caspases and their substrates. Cell Death Differ. 24:1380-1389. https://doi.org/10.1038/cdd.2017.44.

Kateete, D. P., U. Kabugo, H. Baluku, L. Nyakarahuka, S. Kyobe, M. Okee, C. F. Najjuka, and M. L. Joloba. 2013. Prevalence and antimicrobial susceptibility patterns of bacteria from milkmen and cows with clinical mastitis in and around Kampala, Uganda. PLoS One 8:e63413. https://doi.org/10.1371/journal.pone.0063413.

Koenig, R. L., J. L. Ray, S. J. Maleki, M. S. Smeltzer, and B. K. Hurlburt. 2004. Staphylococcus aureus AgrA binding to the RNAIII-agr regulatory region. J. Bacteriol. 186:7549-7555. https://doi.org/10 .1128/JB.186.22.7549-7555.2004.

Liu, H., S. Li, L. Meng, L. Dong, S. Zhao, X. Lan, J. Wang, and N. Zheng. 2017. Prevalence, antimicrobial susceptibility, and molecular characterization of Staphylococcus aureus isolated from dairy 
herds in northern China. J. Dairy Sci. 100:8796-8803. https://doi .org/10.3168/jds.2017-13370.

Liu, X., Z. Zhang, J. Ruan, Y. Pan, V. G. Magupalli, H. Wu, and J. Lieberman. 2016. Inflammasome-activated gasdermin D causes pyroptosis by forming membrane pores. Nature 535:153-158. https:/ /doi.org/10.1038/nature18629.

Liu, Y., W. Chen, T. Ali, R. Alkasir, J. Yin, G. Liu, and B. Han. 2014. Staphylococcal enterotoxin $\mathrm{H}$ induced apoptosis of bovine mammary epithelial cells in vitro. Toxins (Basel) 6:3552-3567. https:// doi.org/10.3390/toxins6123552.

Löffler, B., M. Hussain, M. Grundmeier, M. Brück, D. Holzinger, G. Varga, J. Roth, B. C. Kahl, R. A. Proctor, and G. Peters. 2010. Staphylococcus aureus Panton-Valentine leukocidin is a very potent cytotoxic factor for human neutrophils. PLoS Pathog. 6:e1000715. https://doi.org/10.1371/journal.ppat.1000715.

Otter, J. A., and G. L. French. 2010. Molecular epidemiology of community-associated meticillin-resistant Staphylococcus aureus in Europe. Lancet Infect. Dis. 10:227-239. https://doi.org/10.1016/ S1473-3099(10)70053-0.

Qiu, J., X. Niu, J. Dong, D. Wang, J. Wang, H. Li, M. Luo, S. Li, H. Feng, and X. Deng. 2012. Baicalin protects mice from Staphylococcus aureus pneumonia via inhibition of the cytolytic activity of $\alpha$-hemolysin. J. Infect. Dis. 206:292-301. https://doi.org/10.1093/ infdis/jis336.

Saïd-Salim, B., B. Mathema, K. Braughton, S. Davis, D. Sinsimer, W. Eisner, Y. Likhoshvay, F. R. DeLeo, and B. N. Kreiswirth. 2005. Differential distribution and expression of Panton-Valentine leucocidin among community-acquired methicillin-resistant Staphylococcus aureus strains. J. Clin. Microbiol. 43:3373-3379. https://doi .org/10.1128/JCM.43.7.3373-3379.2005.

Seol, J. W., S. J. Kang, and S. Y. Park. 2010. Silver ion treatment of primary cultured bovine mammary gland epithelial cell (BMEC) damage from Staphylococcus aureus-derived alpha-toxin. Vet. Res. Commun. 34:33-42. https://doi.org/10.1007/s11259-009-9330-4.
Shi, J., Y. Zhao, K. Wang, X. Shi, Y. Wang, H. Huang, Y. Zhuang, T. Cai, F. Wang, and F. Shao. 2015. Cleavage of GSDMD by inflammatory caspases determines pyroptotic cell death. Nature 526:660-665. https://doi.org/10.1038/nature15514.

Vrieling, M., K. J. Koymans, D. A. Heesterbeek, P. C. Aerts, V. P. Rutten, C. J. de Haas, K. P. van Kessel, A. P. Koets, R. Nijland, and J. A. van Strijp. 2015. Bovine Staphylococcus aureus secretes the leukocidin LukMF' to kill migrating neutrophils through CCR1. MBio 6:e00335. https://doi.org/10.1128/mBio.00335-15.

Wang, W., X. Lin, T. Jiang, Z. Peng, J. Xu, L. Yi, F. Li, S. Fanning, and Z. Baloch. 2018. Prevalence and characterization of Staphylococcus aureus cultured from raw milk taken from dairy cows with mastitis in Beijing, China. Front. Microbiol. 9:1123. https://doi .org/10.3389/fmicb.2018.01123.

Yang, W., H. Li, X. Cong, X. Wang, Z. Jiang, Q. Zhang, X. Qi, S. Gao, R. Cao, and W. Tian. 2016. Baicalin attenuates lipopolysaccharide induced inflammation and apoptosis of cow mammary epithelial cells by regulating NF-kappaB and HSP72. Int. Immunopharmacol. 40:139-145. https://doi.org/10.1016/j.intimp.2016.08.032.

Zhang, B., Z. Y. Liu, Y. Y. Li, Y. Luo, M. L. Liu, H. Y. Dong, Y.-X. Wang, Y. Liu, P.-T. Zhao, F.-G. Jin, and Z. C. Li. 2011. Antiinflammatory effects of matrine in LPS-induced acute lung injury in mice. Eur. J. Pharm. Sci. 44:573-579. https://doi.org/10.1016/j .ejps.2011.09.020.

Zhang, L., J. Gao, H. W. Barkema, T. Ali, G. Liu, Y. Deng, S. Naushad, J. P. Kastelic, and B. Han. 2018. Virulence gene profiles: Alpha-hemolysin and clonal diversity in Staphylococcus aureus isolates from bovine clinical mastitis in China. BMC Vet. Res. 14:63. https://doi.org/10.1186/s12917-018-1374-7.

\section{ORCIDS}

Xuezhang Zhou () https://orcid.org/0000-0001-9048-3170 